\title{
FUNCTION-BASED MATERIAL SELECTION FOR CROSS- COMPONENT LIGHTWEIGHT DESIGN WITHIN THE EXTENDED TARGET WEIGHING APPROACH
}

\author{
Revfi, Sven (1); Kaspar, Jerome (2); Vielhaber, Michael (2); Albers, Albert (1) \\ 1: Karlsruhe Institute of Technology; 2: Saarland University
}

\begin{abstract}
Shortening product development cycles while improving cost efficiency and quality epitomize a key challenge in today's competitive market environment. Integrated approaches simultaneously taking into account a conceptual design, material and processing definition methodologically facilitate the progress of promising product solutions most effectively. However, assorted approaches in the field of lightweight design as well as material selection mostly trying to cover alternative solutions on a component-specific level exclusively, yet.

Thus, this contribution outlines a cross-component material selection for function-based lightweight design within the Extended Target Weighing Approach covering the identification and evaluation of lightweight design potentials. The developed method is based on Ashby's material selection additionally taking into account project objectives for mass, costs and $\mathrm{CO} 2$ emissions in individual functional design spaces. Resulting in material combinations fitting to clearly stated project targets, the product engineer is already supported in an early phase of product development when initially assessing feasible materials for the overall system development.
\end{abstract}

Keywords: Lightweight design, Conceptual design, Early design phases, Target Weighing, Optimisation

\section{Contact:}

Revfi, Sven

Karlsruhe Institute of Technology

IPEK - Institute of Product Engineering

Germany

sven.revfi@kit.edu

Cite this article: Revfi, S., Kaspar, J., Vielhaber, M., Albers, A. (2019) 'Function-Based Material Selection for

Cross-Component Lightweight Design Within the Extended Target Weighing Approach', in Proceedings of the 22nd International Conference on Engineering Design (ICED19), Delft, The Netherlands, 5-8 August 2019. DOI:10.1017/ dsi.2019.278 


\section{INTRODUCTION}

Up to 80 percent of the mass and energy/resource consumption of a product are already defined by the product concept (Leichtbau BW, 2017). To realize a proper lightweight design product concept, it is necessary to select the right material in the right place. In addition to the aforementioned factors of mass and resource consumption, costs play a decisive role. There are various ways of identifying a suitable lightweight design material, for example, with the help of lightweight design indicators (Klein, 2013). These indicators are only based on the material's lightweight design potential. However, the consideration of costs and $\mathrm{CO} 2$ targets results in a multi-criteria problem of material selection. In order to take these various criteria into account, Sirisalee et al. (2003) developed an appropriate procedure applied on individual components. On the basis of this work, the following contribution presents a multi-material design method for different functional design spaces (FDS) of individual components or subsystems while adhering to mass, cost and $\mathrm{CO} 2$ targets of an overall project. The function-based procedure is intended to support the product developer in the systematic selection of materials especially in the early phase of product development, in which materials must be selected that match the project objectives. Thus, the selection is based on reference systems and should result in a reasonable suggestion of materials for individual functional design spaces.

\section{STATE OF THE ART AND LITERATURE REVIEW}

In the past, there have been many scientific and practical attempts with regard to a methodical product development, e. g. Pahl and Beitz (1996) and Ehrlenspiel (2009). These attempts make a distinction between new design, adaptation design and variant design. Based on experience from the industrial environment, Albers et al. (2015) found that products are developed in generations. This model is called PGE - Product Generation Engineering and implies that knowledge from reference systems (e. g., previous product generations or competitor products) is available and can be used for the development of new product generations.

Beside the component-based product development, function-based approaches have been developed. Especially in lightweight design, where the lightweight optimum of the overall system is not necessarily the combination of the optimized individual components, the function-based approaches showed great potential (Revfi et al., 2018). Based on the findings of Feyerabend (1991), who transferred the approach of value analysis to lightweight design, different approaches were developed. They essentially all contain the development of lightweight design-optimized products based on product functions (Ponn and Lindemann, 2011; Albers et al., 2013; Posner et al., 2013).

Apart from these more constructive approaches, however, the consideration of manufacturing and material-specific capabilities as well as restrictions directly within development methodologies become more and more indispensable. Thus, various efforts emerged in particular to a systematic selection of materials (Ashby, 2011; Dieter, 1983; Farag, 2014; Reuter, 2014) additionally with partly concrete processing-related correlations (Illgner, 1979). Starting with the gathering of materialrelevant requirements and the subsequent screening in view of correspondingly feasible material classes according to hard/binding criteria but still irrespective of objective functions and free variables (rough selection), a specific selection of experimentally confirmed material types with slight information about shape factors constitutes the final stage (Ashby, 2011). Today, this procedure is extended by using the computer-based material database Cambridge Engineering Selector (CES) by Granta Design Ltd., primarily to quickly determine alternative solutions to the already applied materials at the last stage of material selection. Herein, and compared to other computer-aided expert systems, the graphical output is a two-dimensionally so-called material property chart displaying property-related limits or performance indices also with an ordinary weighted evaluation (Pareto curves). To outline this evaluation in a more detailed way concerning technical, economic and ecological aspects, certain approaches transfer the multi-criteria decision-making formalisms (e. g., AHP, VIKOR or PROMETHEE) also to assess materials (Jato-Espino et al., 2014).

However, the attempts are mostly limited to the proposal of suitable processes for previously selected materials, or vice-versa, and thus often do not holistically provide sufficient support for truly integrated design, material and process-based decisions, i.e. do imperatively need at least one fixed or rather pre-defined dimension when concurrently selecting material and processing (Ashby et al., 2004) or material and design/shape issues (Weaver and Ashby, 1997; Pasini, 2007). 
In addition, the integrated threefold definition should not only be restricted to a purely componentspecific view, merged injudiciously in the end to an assembly. Indeed, and having regard to a nowadays targeted system-efficient multi-material design in lightweight engineering, an earlier inclusion of cross-component aspects is indispensably required (Kaspar and Vielhaber, 2016), particularly relating to a necessitated assessment of the joining process (Prüß et al., 2010; Choudry et al., 2018). Based on this assumption, the contribution of Kaspar et al. (2018a) describe a procedural methodology of a multi-cross-dimensional and multi-criteria decision analysis $\left(\mathrm{MCD}^{2} \mathrm{~A}\right)$.

The arising research question evolving from the state of the art can be therefore be formulated as follows: How can material selection processes based on reference systems support the product developer within function-based cross-component approaches in the early phase of product development in order to find materials matching the project objectives and to come up with a multi-material design.

\section{SYSTEMIC EXTENDED TARGET WEIGHING APPROACH}

Considering the aforementioned state of the art in research, a systemic and function-based material selection method is introduced for an early system lightweight design to support the concept generation in the Extended Target Weighing Approach (ETWA) (see Figure 1), which was initially presented by Albers et al. (2017).

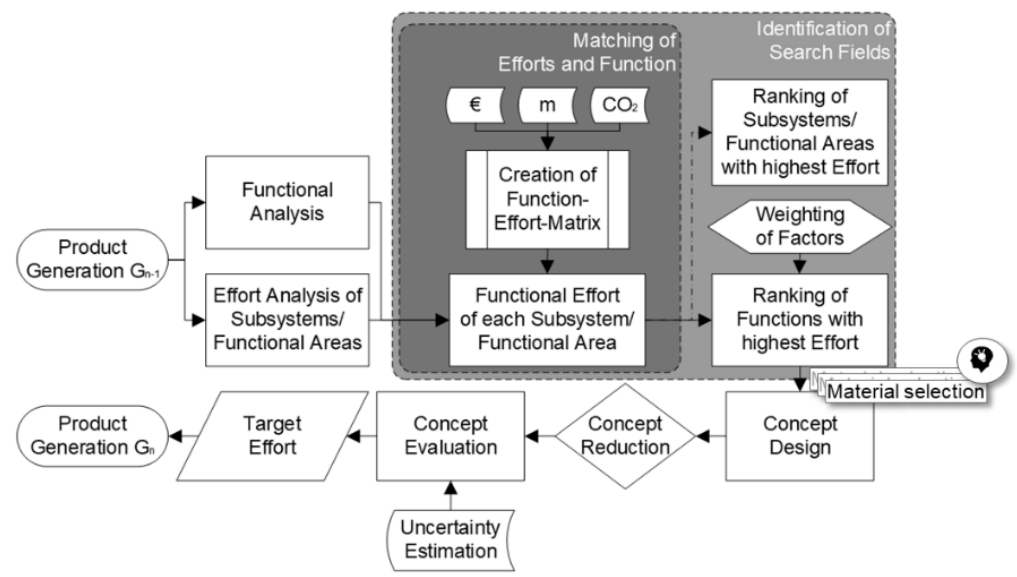

Figure 1. Implementation of a systemic material selection method in the existing workflow of the ETWA according to Albers et al. (2019)

When developing products in generations according to the PGE model, the starting point for the execution of the ETWA is always a reference system, which needs to be optimized in its mass - with additional consideration of costs and $\mathrm{CO} 2$ emissions. The ETWA itself is to be considered as a lightweight design method for system lightweight design, as it supports the product developer in detaching himself from existing component structures (by means of the product description at functional level) and thinking too heavy product functions into new embodiment designs. Therefore, and after the definition of the system to be considered consisting either of only one component or also of application-specific aggregated subsystems, the functions are analyzed. At the same time, the triple consisting of mass, costs and $\mathrm{CO} 2$ data (which is called effort) of the component or subsystems associated with the reference system is collected. Subsequently, an abstraction to the function level takes place by assigning subsystems their percentage share to the function fulfillment in the FunctionEffort-Matrix (see Figure 2 (left)). Since a function can be fulfilled by several subsystems, this procedure reflects the cross-subsystem character of the methodology. At the end of this activity, this results in mass, costs and $\mathrm{CO} 2$ emissions per function. Based on these results, search fields for functions being too heavy can be identified. For this purpose, the functions are first evaluated with regard to their relative importance. Then, the functions are plotted with their efforts over their relative importance. All functions that have efforts above the regression line offer lightweight design potentials (see Figure 2 (right)) and may be converted into new concept ideas in a subsequent step. Thereby, the whole embodiment design can be changed, and thus also the materials. On the one hand, this offers great design freedom, but on the other hand, it also requires an early assessment of whether and with which materials the required material requirements could be met under given project boundary conditions (mass, cost and $\mathrm{CO} 2$ target). 

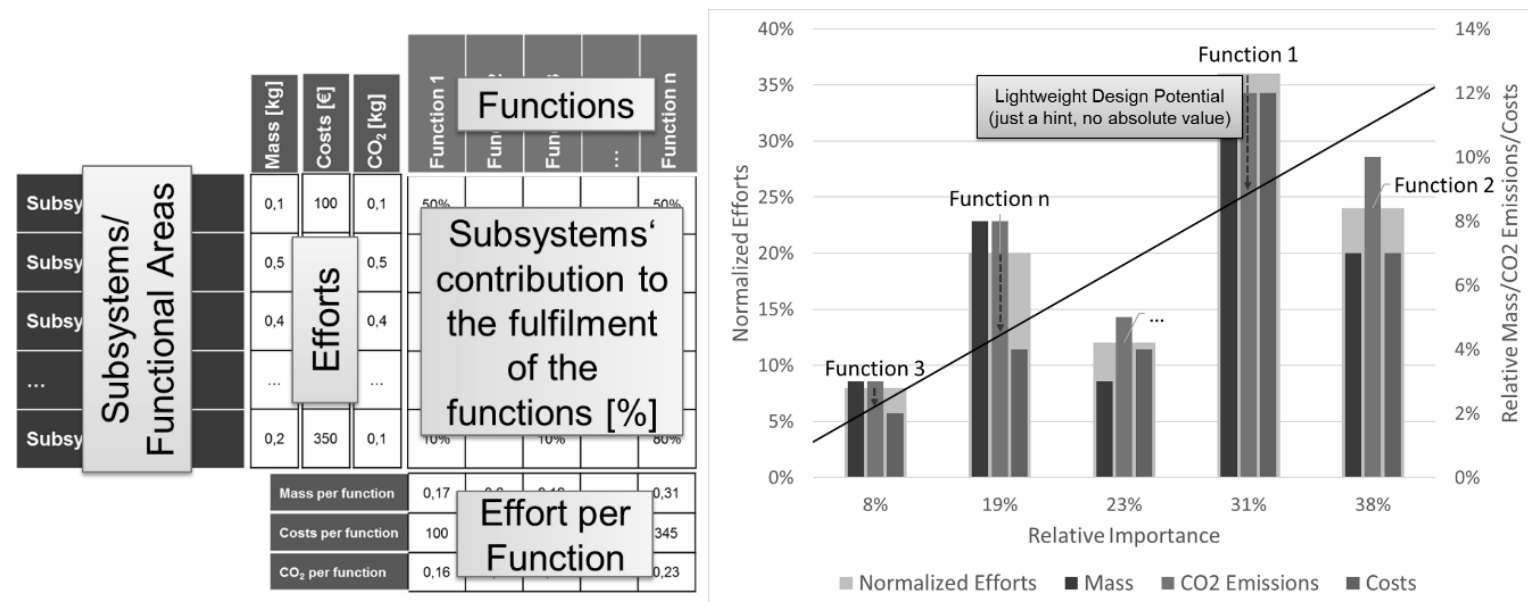

Figure 2. Function-effort-matrix (left) and function portfolio (right) according to Albers et al.

(2018)

The method presented in the following provides only suggestions for materials that could be considered within the project objectives. The idea is to identify material combinations that match the project objectives, to convert them into new concept ideas and then to quickly validate them using real-time simulations. This provides decisive support for concept generation in the early phase of product development. However, a final statement about the suitability of the material can only be made after a simulative and experimental validation has taken place.

\section{DETAILED VIEW ON MATERIAL SELECTION}

Having highlighted the procedural framework in general, a more detailed view on the material selection based on the extended use of Ashby's method is following.

One key to the successful development of new lightweight solutions is multi-material design. In order to support the product developer in the design of multi-material concepts in the early phase of product development, a method based on Ashby's material selection (see Figure 3) is presented in the following paragraphs. The method has been developed to support the concept design phase in the function-based lightweight design method ETWA (see Figure 1).

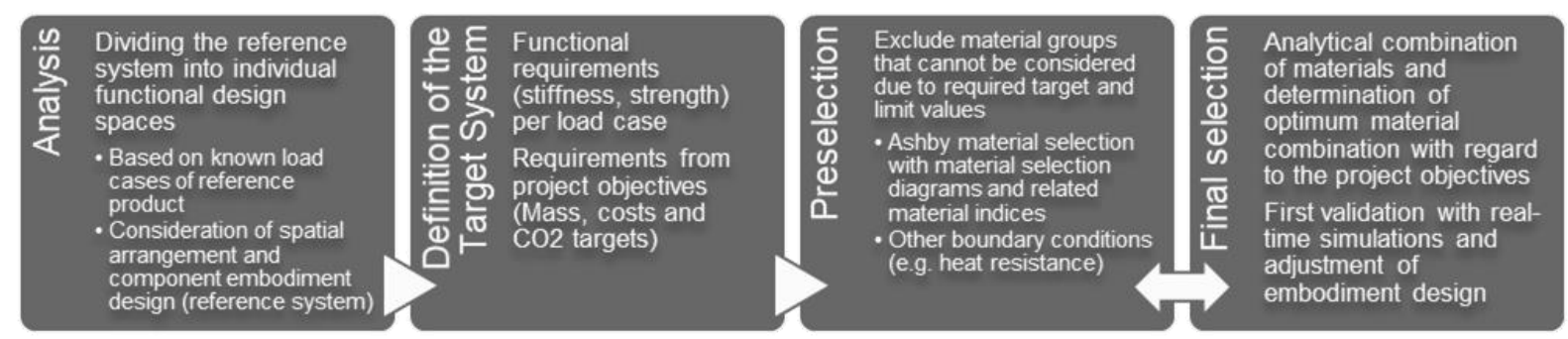

Figure 3. Workflow of the developed method

\subsection{Analysis of the reference system}

The developed material selection method is based on the findings in the ETWA, which were achieved up to the concept design phase (see Figure 1). In particular, this is knowledge about the functions with too much mass, too many costs and too many $\mathrm{CO} 2$ emissions in relation to their relative importance. The functions that are identified as too heavy are pursued to be converted into lighter concepts in the concept phase.

Therefore, the reference system needs to be divided into individual functional design spaces, which are not necessarily following the component structure. For this purpose, the identified functions are traced back to the subsystems which contribute to them with the help of the Function-Effort-Matrix. These subsystems are used to group FDS, i.e. regions in which the functions are performed. Consequently, the function with the greatest lightweight design potential is taken first, remaining functions with lightweight design potential are considered iteratively. Additionally, with the help of knowledge about the load cases of the individual subsystems of the reference system, the FDS can be assigned their 
associated load cases. This allows the functional design spaces to be further subdivided if necessary in order to obtain FDS with the same main load case. Moreover, only one material is allowed per FDS, since this material is the reference for the subsequent method for material selection.

The finer the subdivision, the more differential is the design. However, if too many functional design spaces are combined, the possible materials must be able to withstand all occurring load cases, which leads to less materials passing the selection process. Finally, mass, costs and $\mathrm{CO} 2$ emissions of the reference system can be taken from the Function-Effort-Matrix providing the starting point for the following selection.

\subsection{Definition of the target system}

According to the known procedure of Ashby, material indices for stiffness and strength can be determined for each FDS depending on the load case (see Table 1) identified in the analysis step. The factor ' $\mathrm{X}$ ' needs to be replaced accordingly for mass (X="1"), cost (X="K") or CO2 emissions ( $\mathrm{X}=$ "CO2").

Table 1. Material indices according to Ashby (2011)

\begin{tabular}{|c|c|c|}
\hline Load case & $\begin{array}{l}\text { Material indices } \\
\text { (stiffness) }\end{array}$ & $\begin{array}{l}\text { Material indices } \\
\text { (strength) }\end{array}$ \\
\hline Tension & $\frac{E}{\rho X}$ & $\frac{R_{e S}}{\rho X}$ \\
\hline Bending (plate) & $\frac{E^{1 / 3}}{\rho X}$ & $\frac{R_{e S}^{1 / 2}}{\rho X}$ \\
\hline$\ldots$ & $\ldots$ & $\ldots$ \\
\hline
\end{tabular}

In addition to this well-known procedure, project targets on mass (e. g., mass reduction: $20 \%$ ), cost (e. g., additional costs per kilogram saved: $5 € / \mathrm{kg}$ ) and $\mathrm{CO} 2$ emissions (e. g., $\mathrm{CO} 2$ reduction: $5 \%$ ) are now to be integrated. The subsequent material selection is decisively influenced by these given target values. Based on these objectives, target curves decisively depending on the reference material can be calculated (see Figure 4), e. g. a weight saving of $20 \%$ for the reference material low alloy steel allows approximately $100 \%$ additional costs compared to the initial material.

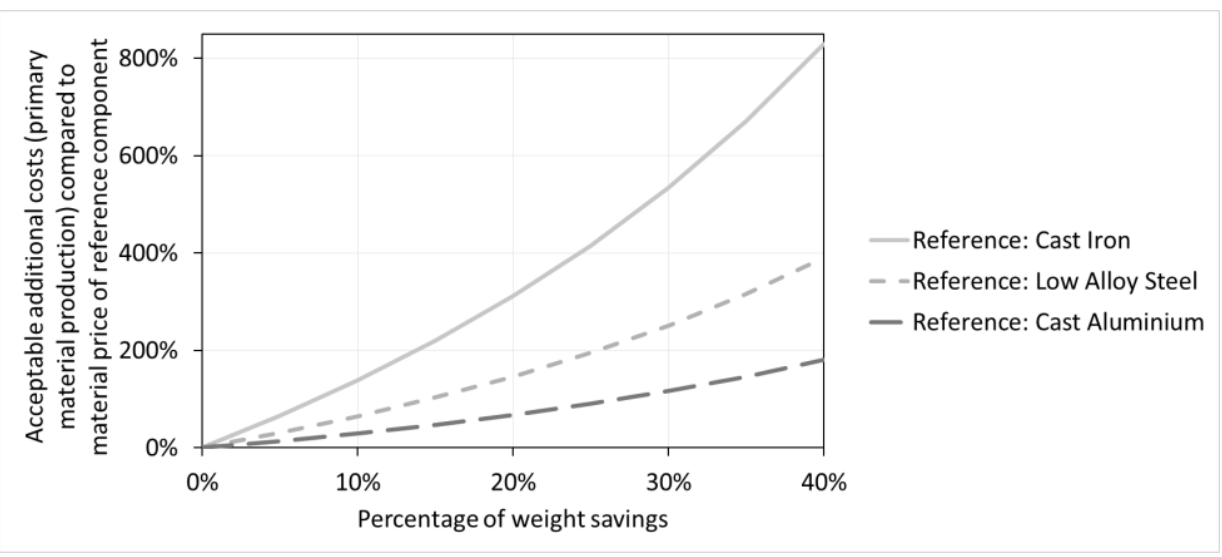

Figure 4. Correlation between permitted additional costs per kilogram saved

As the design space is often a competitive issue, this aspect additionally needs to be considered in the target system definition. Thus, application-dependent cross-section ratios A/A0 of newly developed concepts compared to individual components of the reference functional design space are determined. A0 is the cross-section from the reference product in the considered FDS. The limit of the new cross section A always depends on the exact boundary conditions. This A/A0 limit can be integrated in the material property charts as exclusion criterion in the Preselection phase, see Figure 5 (left).

As the material selection process is based on defined functional design spaces and not exactly refers to single components, shape factors of the formed material will not be considered in detail. Nevertheless, the basic shape (e. g., plate, beam, hollow shaft) of the components is mainly determined by their load case. Therefore, it is assumed that the potential of shape factors is already exploited in the reference product. This assumption is permissible here because the method is based on the PGE, and thus it can be assumed that the knowledge acquired over product generations was used to select the best possible basic shape. 


\subsection{Preselection}

Having all information gathered during the Definition of the Target System, the demands now need to be transferred to material property charts according to Ashby's method. Therefore, material indices are set in relation to the material of the reference system. In doing so, the reference material is always located at point $(1 ; 1)$ in the diagram. Furthermore, specified limits from the Definition of the Target System phase are integrated in the material property charts inside the CES software to consider further goals (see Figure 5). Here on the right side of Figure 5, for example, materials are excluded which are too expensive to meet the project's goals (given in additional costs per kilogram saved) although only their primary production costs are taken into account. The selection procedure has to be conducted for stiffness and strength boundaries for each functional design space. If there are superposed load cases in the FDS, the selection must be made iteratively for all load cases. The materials that meet the strength and stiffness requirements of the first load case are passed on to the second load case. Only materials that have successfully passed all selection steps will be pursued. However, it is not necessary to consider equivalent stresses at this early stage of concept development since later embodiment changes may lead to a different stress distribution. Finally, the individually remaining materials are evaluated and further selected with regard to other hard boundary conditions, such as heat or corrosion resistance. The resulting materials for each functional design space are used for the final selection.
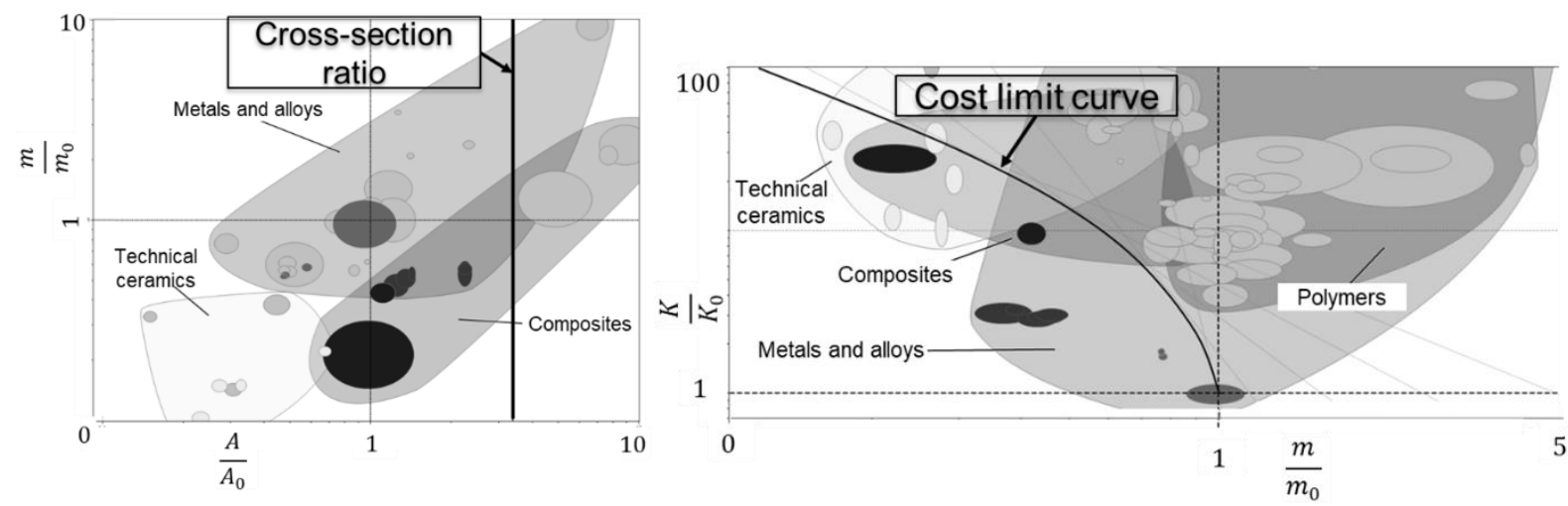

Figure 5. Material property charts with A/AO ratio (left) and cost project target curve (right)

\subsection{Final selection}

The remaining materials for the individually considered functional design spaces then have to be combined in a suitable way in order to achieve the best possible performance of the overall system. For this purpose, the individual results are automatically processed to most-promising material combinations. Afterwards, they are ranked in terms of their achievable mass, cost and $\mathrm{CO} 2$ values (see Table 2).

Table 2. Schematically excerpt of ranked material options for preassigned FDS

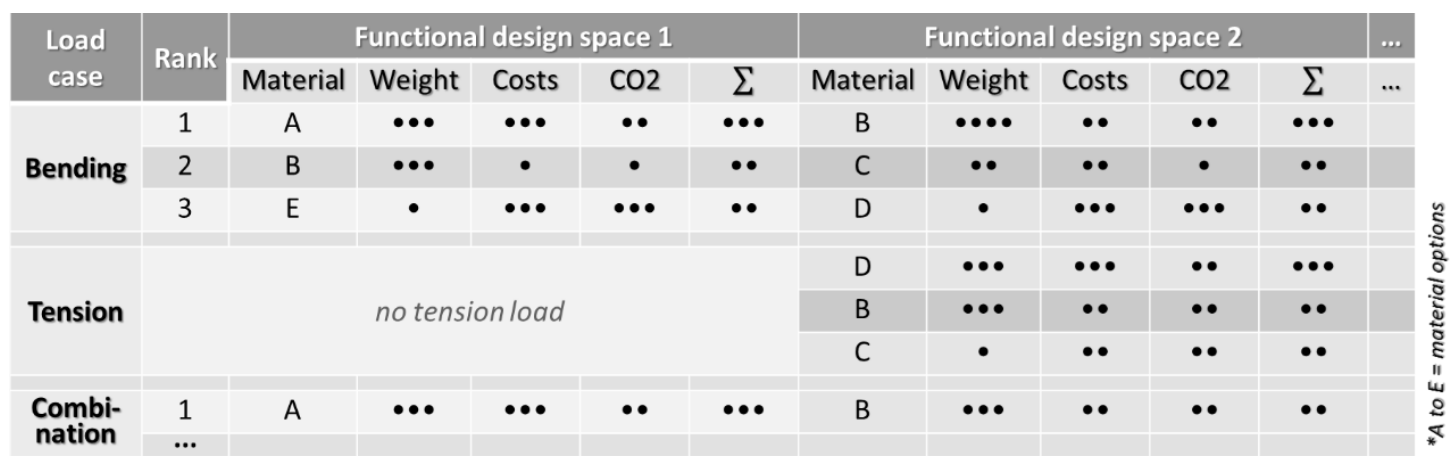

Performing this selection process leads to several material combinations for the functional design spaces. However, since the selection process is based on the existing product generation, only material substitutions have been considered so far. But, material substitutions often do not meet the requirements. For this reason, the developed method involves embodiment adaptation after material selection. For this purpose, the existing assembly from the reference product is imported into a tool for real-time simulations (e. g., ANSYS Discovery Live) and divided into the identified functional design spaces. Subsequently, the materials resulting from the material selection process are assigned to the 
FDS and the simulation model including loads and boundary conditions is built up. The direct feedback of the real-time simulations and the possibility of simple embodiment adaptation allow the generated material combinations to be quickly validated. This validation in no case replaces a more complex FE simulation or experiments, but offers a first indication whether a material concept has the potential to be further pursued. This provides a first knowledge base in the early phase of product development. Furthermore, a better estimation of the achievable mass of the product can be gained based on the adjusted embodiment design. This process iteratively runs through selected material combinations so that a lot of design concepts are generated and validated.

\section{INITIAL APPLICATION EXAMPLE}

The ETWA is used in the following example to optimize a scooter gearbox housing (see Figure 6 (left)) in its mass. In order to keep the example comprehensible, only mass and cost targets are considered. Similarly, it would also be possible to include $\mathrm{CO} 2$ targets. The gearbox housing consists of five components (see Figure 6 (left)) and fulfills the functions shown in Figure 6 (right). The task is to generate new concept ideas. To support the product developer in this task, the developed method is used.
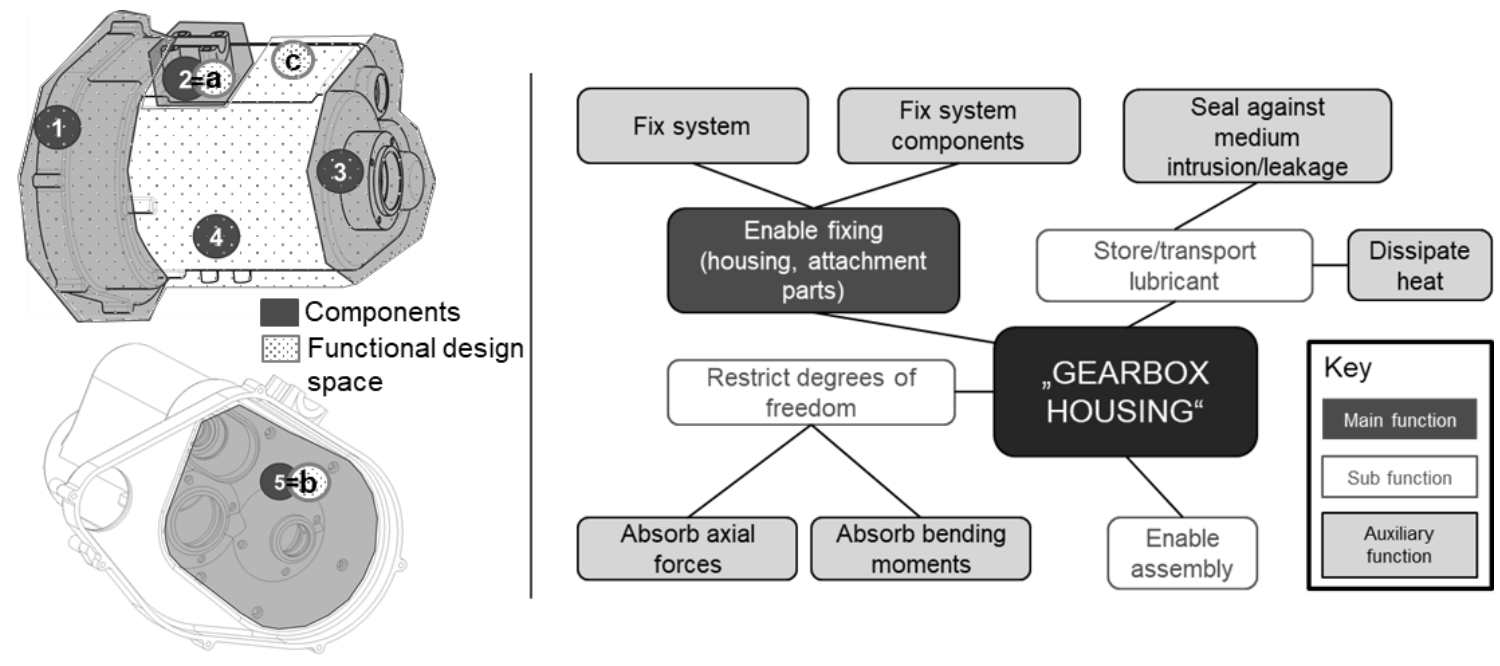

Figure 6. Gearbox housing according to Albers et al. (2018) (left) and its functions according to Albers et al. (2019) (right)

For each function, corresponding requirements (e. g., strength and stiffness, or thermal conductivity) can be identified. For example, the function "Absorb bending moments" must satisfy stiffness and strength requirements, while the function "Dissipate heat" sets requirements for thermal conductivity. In addition, the dominant load cases in the components are determined. For example, all components of the gearbox housing are under bending load, while component 2 is additionally exposed to tensile stress due to the fixing to the frame. Based on the gathered mass and cost data as well as the identified functions, the Function-Effort-Matrix is then created. Therein, the components are assigned by percentage according their contribution to the fulfillment of the function, and thus based on the obtained mass and costs per function, the lightweight design potentials are identified. In case of the present gearbox housing, it turns out that the function "Absorb bending moments" is dedicated as too heavy in relation to its relative importance. This function is followed up here as an example, since it receives a contribution from all components. For all components contributing to this function, it is checked which load cases are present and which additional functions are still to be performed by the respective component. In addition, it is examined which components that are exposed to the same load case are spatially connected. Having these information on requirements, load cases and spatial arrangement, the division of the functional design spaces for the gearbox housing can be carried out as shown in Table 3. These steps are repeated for all functions identified as too heavy in order to obtain a final division of the functional design spaces. This completes the first step of the method, the "Analysis of the Reference System". In the present example, the functional design space division from Table 3 is continued. The functional design spaces are visualized in Figure 6 (left). 
Table 3. Division of the functional design spaces

\begin{tabular}{|c|r|r|}
\hline \multirow{2}{*}{ Functional design space } & \multicolumn{2}{c|}{ Functional areas } \\
\hline a & Mounting (2) & Bending \& Tension \\
\hline b & Location bearing (5) & Bending \& Tension/Pressure \\
\hline c & $\begin{array}{c}\text { Lid side (1), Floating bearing } \\
(3), \text { Centre section (4) }\end{array}$ & Bending \\
\hline
\end{tabular}

Second (Definition of the Target System), the project objectives for material selection have to be defined. In the present example, a mass reduction of $35 \%$ was chosen with permitted additional costs of $3 €$ per kilogram saved. The initial mass of the gearbox housing, which is a student construction, is $11.3 \mathrm{~kg}$. This results in a target mass of $7.3 \mathrm{~kg}$. The underlying costs of the reference system are $3 €$. In the following Preselection step, the required target curves for the ratios of K/K0 over $\mathrm{m} / \mathrm{m} 0$ are converted in the CES and the permissible area ratio of A/A0 (here for the gearbox housing: A/A0 3) is implemented. The selection diagrams are then run through for stiffness and strength iteratively for each load case in each FDS until only those materials remain which meet all set requirements.

In the Final Selection, the remaining materials need to be assessed according to additional requirements, e. g. health issues. Afterwards the resulting materials from the material selection in the individual functional design spaces are combined with each other in such a way that the overall system shows the best possible results with regard to the project objectives. Furthermore, additional topics like manufacturing, joining or existing infrastructure have to be still manually evaluated and included for the final decision. A result of the combination for the example of the gearbox housing is shown in Table 4. Afterwards, the chosen material selection is validated with the help of ANSYS Discovery Life to assess the potential of the material combination and to update the required mass and costs for the concept idea.

Table 4. Material combinations in the functional design spaces

\begin{tabular}{|c|c|c|c|c|c|c|}
\hline & $\begin{array}{l}\text { Functional design } \\
\text { space a }\end{array}$ & $\begin{array}{l}\text { Functional design } \\
\text { space b }\end{array}$ & $\begin{array}{l}\text { Functional design } \\
\text { space c }\end{array}$ & $\begin{array}{l}\text { Mass } \\
{[\mathrm{kg}]}\end{array}$ & $\begin{array}{c}\text { Costs } \\
{[€]}\end{array}$ & $\begin{array}{l}\text { LW costs } \\
{[€ / \mathrm{kg}]}\end{array}$ \\
\hline Combination 1 & Cast Iron & Cast Iron & Cast Al-Alloys & 6 & 6.6 & $0.7 / 3$ \\
\hline Combination 2 & $\begin{array}{l}\text { CFRP, epoxy matrix } \\
\text { (isotropic) }\end{array}$ & Medium Carbon Steel & $\begin{array}{l}\text { Wrought Magnesium } \\
\text { Alloys }\end{array}$ & 4.5 & 9.7 & $1.0 / 3$ \\
\hline Combination 3 & Medium Carbon Steel & $\begin{array}{l}\text { Age-hardening wrought } \\
\text { Al-alloys }\end{array}$ & $\begin{array}{l}\text { Wrought Magnesium } \\
\text { Alloys }\end{array}$ & 4 & 8.1 & $0.7 / 3$ \\
\hline
\end{tabular}

\section{DISCUSSION, CONCLUSION AND OUTLOOK}

This contribution presents a method for a systemic material selection based on a reference system to support the product engineer in the early phase of product development. In doing so, it is included in the function-based lightweight design method Extended Target Weighing Approach (ETWA). Based on the functions identified in the ETWA and the occurring load cases, functional design spaces are defined for which possible materials are determined by running through an adapted Ashby's material selection procedure iteratively. For this purpose, project objective curves are integrated to exclude materials not matching the project targets. In order to find the optimal material combination, all materials in the different functional design spaces are combined, embodiment is adjusted and the final values for mass, costs and $\mathrm{CO} 2$ emissions are determined. Being applied to an exemplary application case of a gearbox housing, the potentials and challenges of the developed method are ultimately being discussed below.

\subsection{Potentials and challenges of the method regarding material combinations}

With regard to the aforementioned approach, it is possible to initially support the product developer already in the early phase of product development with a systematic material selection under consideration of project objectives. The result of this method is a basic combination of all possible materials for all determined functional design spaces which fit to the project targets in a simplified and quick manner with respect to a first draft of pursuable concept ideas. Subsequently, the lightest, cheapest and most sustainable solution alternative can primarily be selected. 
As the input from the ETWA is based on functions which can be fulfilled by several components or subsystems, the method supports cross-component solutions. Consequently, the method particularly supports a multi-material engineering for system lightweight design.

Due to the simplification of the load cases required to conduct the material selection supported by the Ashby approach, however, the product developer must be aware that the method only provides an initial material selection support and cannot be used without an additional computational proof of stiffness and strength. In addition, only material properties, raw material costs and $\mathrm{CO} 2$ data for primarily production and recycling of the material are taken into account as rough indications to fundamentally assess the potential of different materials regarding individual functional design spaces, i.e. the cost per kilogram saved, amongst others, does not include monetary aspects on manufacturing, assembly and disassembly processes yet. An extension regarding processing aspects must be provided accordingly. As a result, probably the greatest challenge of this procedure is to broaden the relationship between a technologically producible material and shape being extremely simplified, since it is only based on the specific material indices. Therefore, the actually achievable target values depend decisively on the iteratively elaborated final product design, additionally using promising real-time simulation tools.

Notwithstanding this, and resulting in different, partly atypical material suggestions for various adjacent subsystems, this adds the challenging part of choosing appropriate joining technologies in the end.

\subsection{Joining selection as an essential part}

Picking up this last aspect of a joinable material combination in more detail (e. g., diversified thermal expansions and thermal resistances as well as disharmonious electro-chemical corrosion behavior), further on this issue could principally not guarantee a general feasibility in certain circumstances (e. g., strength-driven design but just gluing options). Moreover, this could potentially lead to additional mass, costs and thus also environmental consequences if a further modification is indispensably necessary (e. g., added specific flange type or thickening of joint section area for thermal joints). This challenge of including a purposive joining technology directly at the initial conceptual phase of multimaterial product development is not yet taken into account adequately in this method and just marginally in general scientific literature (Edwards and Deng, 2007), i.e. to this point mostly deliver a most suitable combination of materials on subsystem level without considering the individual joinability. However, assessing both aspects inherently already in the conceptual design stage needs to be focused in further research work as an essential part, and thus stops still acting reactively with many more iteration loops leading to vast re-engineering costs and extended development cycles despite having just adjusted solution alternatives with generally lower outcomes. In doing so, the focus may not only be restricted to the actual assembly process. Moreover, although monetary and non-monetary operating expenses for the mandatorily prescribed disassembly process should be noted since several combinations (e. g., aluminum class) are very demanding to segregate or recycle in the end-of-life phase, mostly for thermally bonded (e. g., welded aluminum) or hybrid joint multi-material structures. Consequently, for example, a best material for one component and another could be even worse in the ranking when adjacent joining aspects are ought to be added, and thus a separately second or third best evaluated material solution could be given precedence, e. g. in term of a cost-efficient joining possibility. To systematically approach this matter, a concurrent assessment requires a two-stage evaluation process; first, an individual assessment model for materials followed by the joining technologies, and second its concurrent interrelations regarding impact criteria of both (e. g., joint surface, service temperature, tolerances) along with their mutual ranking (Kaspar et al., 2018b).

This integrated view of material and joining technology within previously assigned functional design spaces by ETWA is supposed to be investigated in more detail in Kaspar et al. (2019).

\section{REFERENCES}

Albers, A., Bursac, N. and Wintergerst, E. (2015), "Produktgenerationsentwicklung - Bedeutung und Herausforderungen aus einer entwicklungsmethodischen Perspektive", Stuttgarter Symposium für Produktentwicklung 2015, Stuttgart.

Albers, A., Moeser, G. and Revfi, S. (2018), "Synergy effects by using SysML models for the lightweight design method "extended target weighing approach"“, Procedia CIRP, Vol. 70, pp. 434-439.

Albers, A., Revfi, S. and Spadinger, M. (2017), "Extended target weighing approach - Identification of lightweight design potential for new product generations", Proceedings of the 21 st International Conference on Engineering Design (ICED17), Vancouver, August 21-25, The Design Society, Glasgow, pp. 367-376. 
Albers, A., Revfi, S. and Spadinger, M. (2019), "Funktionsbasierte Entwicklung leichter Produkte”, In: Henning, F. and Moeller, E. (Eds.), Handbuch Leichtbau. Methoden, Werkstoffe, Fertigung. München, Carl Hanser Verlag. [in press].

Albers, A., Wagner, D., Ruckpaul, A., Hessenauer, B., Burkardt, N. and Matthiesen, S. (2013), "Target Weighing - A New Approach for Conceptual Lightweight Design in Early Phases of Complex Systems Development", Proceedings of the 19th International Conference on Engineering Design (ICED 13), Seoul, August 19-22, The Design Society, Glasgow, pp. 301-310.

Ashby, M.F., Brechet, Y.J.M., Cebon, D. and Salvo, L. (2004), "Selection strategies for materials and processes”, Materials \& Design, Vol. 25, pp. 51-67. https://doi.org/10.1016/S0261-3069(03)00159-6

Ashby, M.F. (2011), Materials Selection in Mechanical Design, Butterworth-Heinemann, Oxford. https://doi.org/10.1016/C2009-0-25539-5

Choudry, S.A., Kaspar, J., Alber, U. and Landgrebe, D. (2018), "Integration of an assessment methodology for the selection of joining technologies in lightweight engineering", Procedia CIRP, Vol. 70, pp. 217-222. https://doi.org/10.1016/j.procir.2018.02.034

Dieter, G.E. (1983), Engineering Design: A Materials and Processing Approach, Mc-Graw-Hill, New York.

Edwards, K.L. and Deng, Y.-M. (2007), "Supporting design decision-making when applying materials in combination”, Materials and Design, Vol. 28, pp. 1288-1297. https://doi.org/10.1016/j.matdes.2005.12.009

Ehrlenspiel, K. (2009), Integrierte Produktentwicklung. Denkabläufe, Methodeneinsatz, Zusammenarbeit. 4. Carl Hanser Verlag GmbH \& Co. KG, Aufl. München. https://doi.org/10.3139/9783446421578

Farag, M.M. (2014), Materials and Process Selection for Engineering Design, CRC Press, Boca Raton (FL).

Feyerabend, F. (1991), Wertanalyse Gewicht: Methodische Gewichtsreduzierung - am Beispiel von Industrierobotern, Paderborn, Univ., Dissertation, 1991, VDI-Verl, Düsseldorf

Illgner, K.-H. (1979), "Werkstoffauswahl für den Konstrukteur”, In: Verein Deutscher Ingenieure, VDI-Z 121 No. 20 - Oktober (II), Verein Deutscher Ingenieure, VDI-Verlag, Dusseldorf.

Jato-Espino, D., Castillo-Lopez, E., Rodriguez-Hernandez, J. and Canteras-Jordana, J.C. (2014), “A review of application of multi-criteria decision making methods in construction", Automation in Construction, Vol. 45, pp. 151-162. https://doi.org/10.1016/j.autcon.2014.05.013

Kaspar, J. and Vielhaber, M. (2016), "Cross-Component Systematic Approach for Lightweight and MaterialOriented Design”, DS 85-1: Proceedings of NordDesign 2016, Vol. 1, pp. 332-341.

Kaspar, J., Choudry, S.A., Landgrebe, D. and Vielhaber, M. (2018a), "Concurrent and geometry-dependent selection of material and joining technology - An initial utility-based systematic decision-making tool", 2018 Annual IEEE International Systems Conference (SysCon), pp. 767-774.

Kaspar, J., Choudry, S.A. and Vielhaber, M. (2018b), "Concurrent selection of material and joining technology holistically relevant aspects and its mutual interrelations in lightweight engineering", Procedia CIRP, Vol. 72, pp. 780-785. https://doi.org/10.1016/j.procir.2018.03.093

Kaspar, J., Revfi, S., Albers, A. and Vielhaber, M. (2019), "Cross-component material and joining selection for functional lightweight design based on the extended target weighing approach - a detailed application example", Procedia CIRP. (submitted paper under review)

Klein, B. (2013), Leichtbau-Konstruktion, Springer, Wiesbaden. https://dx.doi.org/10.1007/978-3-8348-9965-1

Leichtbau, B.W. (2017), "Weniger ist mehr. Design.”, available at: https://www.leichtbaubw.de/leichtbau/unsere-mission.html (accessed 27 November 2018)

Pahl, G. and Beitz, W. (1996), Engineering Design: A Systematic Approach, Springer, Berlin. https://dx.doi.org/10.1007/978-1-4471-3581-4

Pasini, D. (2007), "Shape transformers for material and shape selection of lightweight beams", Materials \& Design, Vol. 28, pp. 2071-2079. https://doi.org/10.1016/j.matdes.2006.05.028

Ponn, J. and Lindemann, U. (2011), Konzeptentwicklung und Gestaltung technischer Produkte, Springer Berlin Heidelberg, Berlin, Heidelberg.

Posner B., Binz H. and Roth D. (2013), "Operationalisation of the value analysis for design for lightweight: The function mass analysis", Proceedings of the 19th International Conference on Engineering Design (ICED13), Seoul, August 19-22, 2013, The Design Society, Glasgow, pp. 271-280.

Prüß, H., Stechert, C. and Vietor, T. (2010), "Methodik zur Auswahl von Fügetechnologien im Multimaterialsystemen”, In: Krause, D., Paetzold, K. and Wartzak, S., Design for X: Beiträge zum 21. DfX-Symposium, TuTech Verlag, Hamburg, pp. 131-142.

Reuter, M. (2014), Methodik der Werkstoffauswahl: Der systematische Weg zum richtigen Material, Carl Hanser Verlag, Leipzig.

Revfi, S., Albers, A. and Stegmiller, M. (2018), "Target Weighing Approach: Study to evaluate the benefits of a methodical approach in comparison to classical company processes for the identification of lightweight design potentials", DS 91: Proceedings of NordDesign 2018.

Sirisalee, P., Ashby, M.F., Parks, G.T. and Clarkson, P.J. (2004), "Multi-criteria material selection in engineering design", Adv. Eng. Mater., Vol. 6 No. 1-2, pp. 84-92. https://doi.org/10.1002/adem.200300554

Weaver, P.M. and Ashby, M.F. (1997), "Material limits for shape efficiency", Progress in Materials Science, Vol. 41, pp. 61-128. https://doi.org/10.1016/S0079-6425(97)00034-0 